\title{
Evidence for Two Calcium-Dependent Potassium Conductances in Lizard Motor Nerve Terminals
}

\author{
Kiichiro Morita ${ }^{\mathrm{a}}$ and Ellen F. Barrett \\ Department of Physiology and Biophysics, University of Miami School of Medicine, Miami, Florida 33101
}

Action potentials and afterpotentials were recorded with a microelectrode inserted into lizard motor axons within a few millimeters of their motor terminals. In the presence of $1 \mathrm{mM}$ 4-aminopyridine (4-AP), the duration of the action potential recorded near motor terminals was $\mathrm{Ca}$-sensitive: repolarization was more rapid when bath [Ca] was elevated, and became slower when bath [Ca] was removed or when 0.1 $1 \mathrm{~mm}$ Mn was added. Repolarization was also slowed following addition of 3-10 nM charybdotoxin or 100-300 $\mu \mathrm{M}$ tetraethylammonium (TEA) to the bath, and following intraaxonal injection of the $\mathrm{Ca}$ buffer BAPTA. These results, in agreement with published extracellular recordings, indicate that the motor nerve terminal membrane contains rapidly activating, Ca-activated $\mathrm{K}$ channels.

When these (and other) $K$ channels were blocked by 10 mM TEA, the action potential recorded near motor terminals was followed by Ca-dependent depolarizing afterpotentials, followed in turn by a slow hyperpolarizing afterpotential (h.a.p.) that lasted several seconds. This slow h.a.p. was also Ca-sensitive: it became larger with increasing bath [Ca] and was abolished by removal of bath [Ca] and by addition of $1 \mathrm{~mm} \mathrm{Mn}$. Intra-axonal injection of BAPTA reduced the amplitude of the slow h.a.p., and prolonged injections promoted repetitive discharge. The slow h.a.p. following single action potentials was observed in $100 \mu \mathrm{m}$ ouabain and in $\mathrm{K}$-free solutions and thus is pharmacologically distinct from the hyperpolarization that follows tetanic stimulation. The slow h.a.p. was selectively inhibited by $100 \mathrm{~nm}$ apamin, but persisted in $100 \mathrm{~nm}$ charybdotoxin. This afterpotential was enhanced by 0.1-1 mM 4-AP and by the dihydropyridine Bay K $8644(0.1-1 \mu \mathrm{M})$. These results suggest that the slow h.a.p. in lizard motor nerve terminals is mediated by Ca-activated $K$ channels that can be activated near the resting potential and are pharmacologically distinct from the Ca-activated $K$ channels that contribute to action potential repolarization. The slow h.a.p. was enhanced by 0.1-1 mm caffeine and inhibited by $100 \mu \mathrm{M}$ procaine, raising the possibility that this afterpotential may be activated not only by $\mathrm{Ca}$ entering via

\footnotetext{
Received Oct. 2, 1989; revised Feb. 21, 1990; accepted Feb. 26, 1990.

This work was supported by grants NS 12404 and GM 30377 from the National Institutes of Health. Dr. Ellen McGlade-McCulloh assisted in the experiments involving procaine. We thank Drs. John Barrett and Gabriel David for reading preliminary versions of the manuscript and the reviewers of this manuscript for their thoughtful comments.

Correspondence should be addressed to Dr. Ellen F. Barrett, Department of Physiology and Biophysics, University of Miami School of Medicine, P.O. Box 016430 , Miami, FL 33101.

a Present address: Department of Autonomic Physiology, Medical Research Institute, Tokyo Medical and Dental University, Iokyo, 101, Japan.

Copyright (c) 1990 Society for Neuroscience $0270-6474 / 90 / 082614-12 \$ 03.00 / 0$
}

the plasma membrane, but also by $\mathrm{Ca}$ released from intraterminal stores.

Vertebrate motor nerve terminals contain a much higher density of depolarization-activated $\mathrm{Ca}$ channels than their parent myelinated axon (Katz and Miledi, 1969; Morita and Barrett, 1989). Current through these $\mathrm{Ca}$ channels, combined with the passive depolarizing afterpotential generated in the myelinated portion of the axon (Barrett and Barrett, 1982), would, if unopposed, promote repetitive discharge in motor terminals. However, under normal physiological conditions motor terminals rarely discharge repetitively, suggesting that motor terminals contain sufficient repolarizing conductance systems to offset the extra depolarizing effect of terminal Ca channels. The effects of tetracthylammonium (TEA) and aminopyridines on extracellular recordings indicate that vertebrate motor nerve terminals do contain several types of $\mathrm{K}$ current (Brigant and Mallart, 1982; Gundersen et al., 1982; Mallart, 1984; Tabti et al., 1989). One of these terminal $\mathrm{K}$ currents is Ca-dependent, inhibited by TEA and charybdotoxin, and contributes to action potential repolarization in terminals whose potassium conductance has been reduced by aminopyridines (mouse: Mallart, 1985; Anderson et al., 1988; frog: David and Yaari, 1986; lizard: Angaut-Petit et al., 1989; Lindgren and Moore, 1989). We present intraaxonal recordings from lizard axons impaled near their motor terminals that confirm the existence of this type of Ca-activated K current.

We also present evidence that these motor nerve terminals have an additional type of Ca-activated $\mathrm{K}$ current that is IEAresistant and apamin-sensitive. This current contributes to a prolonged hyperpolarizing afterpotential (h.a.p.) in TEA-trcated terminals and is pharmacologically similar to currents that contribute to the prolonged h.a.p. recorded in vertebrate motoneuron somata (frog: Barrett and Barrett, 1976; cat: Krnjevic et al., 1978; Zhang and Krnjevic, 1987; turtle: Hounsgaard et al., 1988).

An abstract describing portions of this work has been presented (Morita and Barrett, 1988).

\section{Materials and Methods}

Experiments were performed on motor axons innervating the ceratomandibularis muscle of small lizards (Anolis sagrei), using techniques similar to those described in Morita and Barrett (1989). Unless otherwise noted, the physiological saline perfusing the preparation contained (mM) $\mathrm{NaCl} 157, \mathrm{KCl} 4, \mathrm{CaCl}_{2} 2, \mathrm{MgCl}_{2} 2$, glucose 5, and PIPES [piperazine-N,N'-bis(2-ethanesulfonic acid)] buffer 1 (pH 7.0-7.4). Superfusing solutions were changed (within a few minutes) using a Gilson peristaltic pump (MP2).

Axonal action potentials were usually evoked by applying suprathreshold depolarizing pulses $(20 \mu \mathrm{sec}-1 \mathrm{msec}$, at $\leq 0.1 \mathrm{~Hz}$ ) to the nerve trunk via a suction electrode. Muscle contractions were blocked with carbachol 


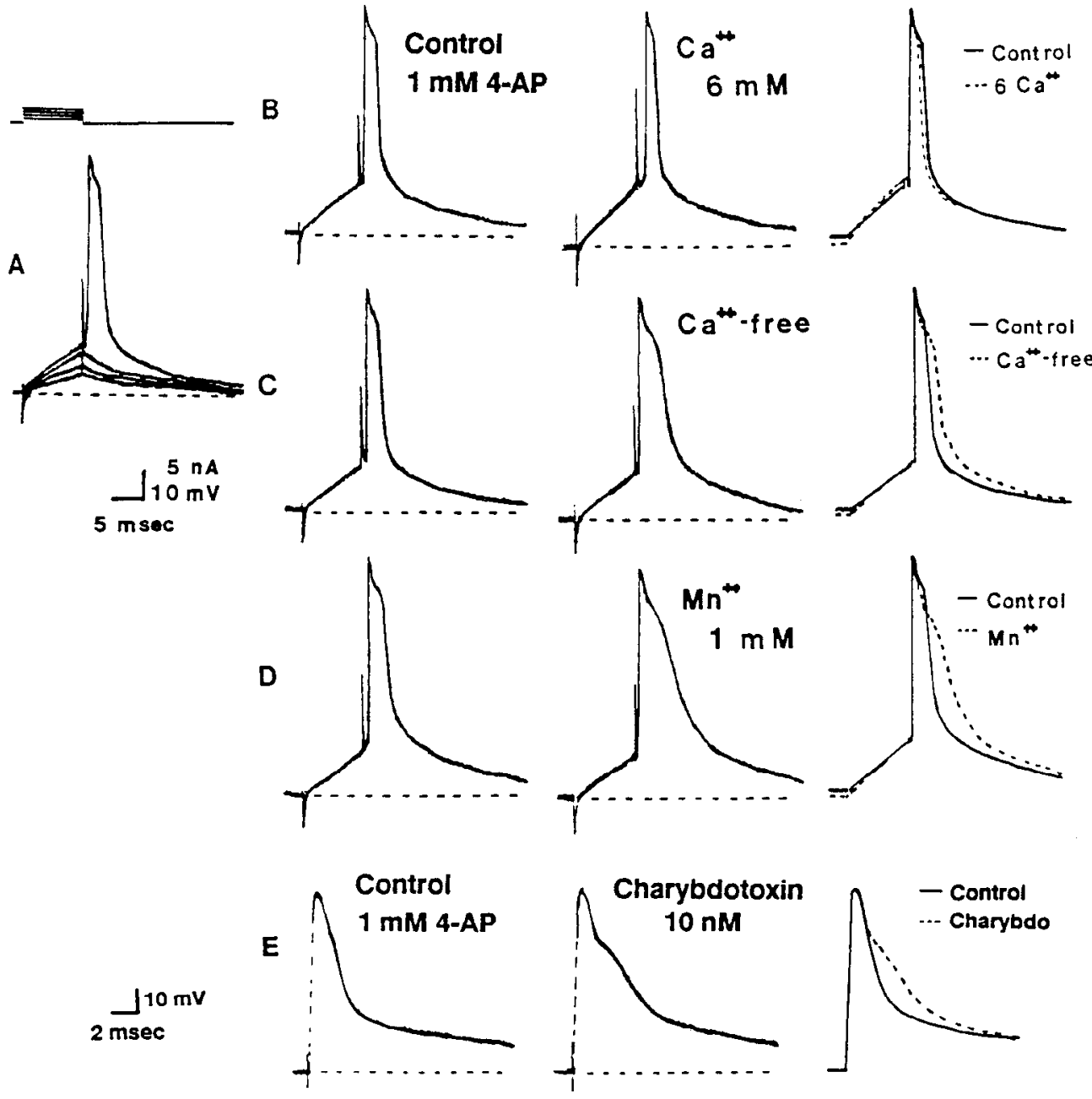

Figure 1. Ca dependence and charybdotoxin sensitivity of action potential repolarization in axons bathed in $1 \mathrm{~mm}$ 4-AP and impaled near their motor terminals. $A$, Superimposed records of axonal response to 4 levels of depolarizing current ( 3 subthreshold and 1 suprathreshold) injected via the recording microelectrode. Upper traces show current, lower traces voltage. $B-E$, Left traces show action potential in control $2 \mathrm{~mm}$ Ca. Middle traces show action potential in $6 \mathrm{~mm} \mathrm{Ca}(B)$, when Ca was omitted from the bath $(C)$, when $1 \mathrm{~mm}$ $\mathrm{Mn}$ was added to the normal $2 \mathrm{mM} \mathrm{Ca}$ solution $(D)$, and $6 \mathrm{~min}$ after $10 \mathrm{~nm}$ charybdotoxin was added to the bath $(E)$. Dashed lines in left and middle traces show baseline. Records at right superimpose control (solid line) and experimental (dashed line) action potentials. Action potential repolarization became faster in $6 \mathrm{~mm} \mathrm{Ca}$ and slower in $\mathrm{Ca}$-free media and in the presence of $\mathrm{Mn}$ or charybdotoxin. Records in $A-D$ came from the same axon, whose resting potential was $-80 \mathrm{mV}$ in control solution and hyperpolarized $2-3 \mathrm{mV}$ in the modified solutions. Action potentials in $E$ were evoked by stimulation of the nerve trunk, and the resting potential was $-78 \mathrm{mV}$.
(30-100 $\mu \mathrm{M}$ ). Intra-axonal recordings were usually obtained using glass micropipettes filled with $0.5 \mathrm{M}$ potassium sulfate (tip resistances 50 $100 \mathrm{M} \Omega$ ), inserted into the internode of a visualized axon using a piezoelectric device (Frederick Haer). In some cases this micropipette was used to pass current into the axon via a bridge circuit (e.g., Fig. $1 A$ ). In some experiments the recording micropipette was filled with the calcium buffer bis (o-aminophenoxy) ethane- $N, N, N^{N}, N^{\gamma}$-tetraacetic acid (BAPTA, $100 \mathrm{~mm}$ in $1 \mathrm{M} \mathrm{KCl}$ or $0.6 \mathrm{M} \mathrm{K}_{2} \mathrm{SO}_{4}$ ). The tip resistance of these pipettes was 50-100 M , and BAPTA was injected with a hyperpolarizing current of $0.2-1.5 \mathrm{nA}$ for periods of up to $10 \mathrm{~min}$. Intra-axonal injection of comparable currents from pipettes filled with only $\mathrm{KCl}$ did not mimic the effects of BAPTA injection. Most recordings were made within 1 $\mathrm{mm}$ of the most distal motor terminals. Recorded action potentials and afterpotentials were amplified and stored using conventional techniques (Morita and Barrett, 1989); action potential amplitudes were truncated in records illustrating the slow hyperpolarizing afterpotential.

All recordings in TEA (Aldrich) were made after at least a 30 min exposure, to allow time for TEA to diffuse to potassium channels in the internodal axolemma (Barrett et al., 1988). Charybdotoxin was kindly provided by Dr. Chris Miller of Brandeis University and by Dr. Gregory Kaczorowski of Merck, Sharp and Dohme Research Laboratories. Bay K 8644 and nitrendipine were gifts from Dr. Alexander Scriabine of Miles Laboratories. Other reagents were obtained from Sigma.

\section{Results}

\section{In 4-aminopyridine}

Repolarization of the action potential is Ca-sensitive near terminals

In normal physiological saline containing no potassium channel blockers the repolarization of the intra-axonally recorded action potential is not sensitive to bath [Ca], regardless of whether the recording electrode is inserted close to or distant from the motor terminals (Barrett and Barrett, 1982). Addition of $1 \mathrm{~mm}$ 4-aminopyridine (4-AP) to the bath produces changes in the action potential that vary with the site of recording. At recording sites remote $(>5 \mathrm{~mm})$ from terminals, this concentration of 4-AP approximately doubles the duration of the action potential, but action potential configuration remains insensitive to bath [Ca] (Barrett et al., 1988). For recording sites near terminals, the main focus of this paper, the late falling phase of the action potential is especially prolonged in 4-AP (Fig. $1 A$ ). This delayed repolarization resembles the $\mathrm{Ca}$-dependent plateau that follows action potentials in some cells, but its response to changes in bath [Ca] were opposite to those expected for a Ca-dependent plateau: repolarization became faster when bath [Ca] was increased from 2 to $6 \mathrm{~mm}$ (Fig. $1 B$ ) and became slower when bath [Ca] was removed (Fig. $1 C$ ) or when $1 \mathrm{~mm}$ Mn was added (Fig. $1 D$ ). Similar results were obtained in 4 additional axons.

These results suggest that the plateau on the repolarizing phase of the juxtaterminal action potential is due to inhibition by 4-AP of potassium current(s) that are especially prominent in motor terminals. When these currents are inhibited, action potential repolarization appears to be controlled by a separate potassium current activated by $\mathrm{Ca}$ influx into the terminals. When $\mathrm{Ca}$ influx is blocked or reduccd, this Ca-dependent potassium current is not activated, and action potential repolari- 


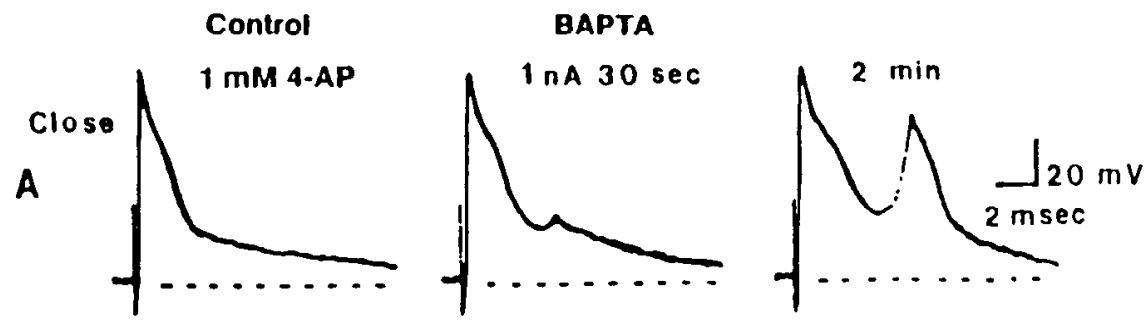

Figure 2. Effects of injecting BAPTA into axons bathed in $1 \mathrm{~mm}$ 4-AP. $A$, In an axon impaled near its motor terminals BAPTA injection (1 nA, $30 \mathrm{sec}-$ $2 \mathrm{~min}$ ) prolonged action potential repolarization and elicited repetitive discharge. $B$, In an axon impaled at a site distant from its motor terminals BAPTA injection (1 $\mathrm{nA}, 2-5 \mathrm{~min})$ slowed action potential repolarization only slightly. Dashed lines indicate resting potential $(-83 \mathrm{mV}$ in $A,-76 \mathrm{mV}$ in B).
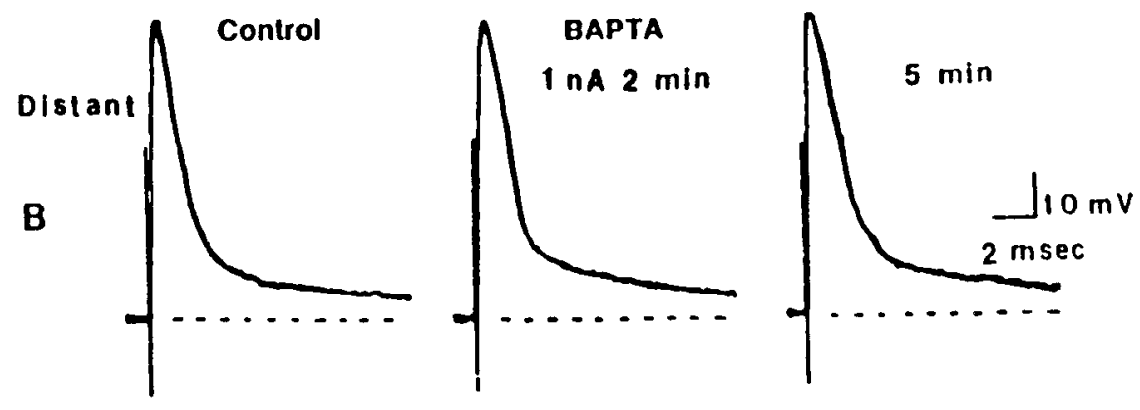

zation is further prolonged. This interpretation is consistent with Tabti et al.'s (1989) extracellular recordings indicating that mouse motor terminal membranes contain both $\mathrm{K}$ currents blocked by aminopyridines and Ca-activated $\mathrm{K}$ currents not blocked by aminopyridines.

\section{Action potential repolarization is slowed by charybdotoxin}

Consistent with the above hypothesis, action potential repolarization in 4-AP was prolonged following addition of charybdotoxin, a component of scorpion venom that blocks certain calcium-activated potassium channels (Fig. $1 E$; Miller et al., 1985). This effect was concentration-dependent: $1 \mathrm{~nm}$ charybdotoxin had no obvious effect $(n=3)$, whereas 3-10 nм consistently prolonged repolarization $(n=4)$, without changing either the resting potential or axonal input resistance. Two axons discharged repetitively in $10 \mathrm{~nm}$ charybdotoxin. Additional experiments demonstrated that $10 \mathrm{nM}$ charybdotoxin had no effect on action potential repolarization in axons bathed in $1 \mathrm{mM} \mathrm{Mn}$ or in Ca-free solution, suggesting that the toxin's effects were specific for calcium-activated channels.

In contrast, apamin (10-100 nM), a component of bee venom that blocks a different subset of calcium-activated potassium channels (Romey and Lazdunsi, 1984), had no effect on action potential repolarization in 4-AP-treated axons $(n=3)$.

Extracellular recordings from motor nerve terminals, as well as single channel recordings from other membranes, suggest that the charybdotoxin-sensitive, Ca-activated $\mathrm{K}$ current is also blocked by millimolar TEA (Mallart, 1985; David and Yaari, 1986; Anderson et al., 1988; Miller, 1988; Lindgren and Moore, 1989). Consistent with these reports, addition of $100-300 \mu \mathrm{M}$ TEA to 4-AP-treated axons selectively prolonged the late phase of the action potential recorded near motor terminals, an effect similar to that of charybdotoxin.

To date, charybdotoxin's reported blocking actions have been restricted to K-selective channels (Miller, 1988). However, our attempts to test directly the K-specificity of the charybdotoxin- sensitive repolarizing current in lizard motor nerve terminals were inconclusive: elevating bath $[\mathrm{K}]$ to $10 \mathrm{~mm}$ depolarized axons by an average of $7 \mathrm{mV}(n=5)$ and slightly prolonged action potential repolarization in 2 of 3 axons, but this prolongation could be duplicated in control solution by depolarizing axons by $7 \mathrm{mV}$ with injected current. Similarly, elimination of $\mathrm{K}$ from the bathing solution initially hyperpolarized axons by an average of $15 \mathrm{mV}(n=5)$ and slightly shortened action potential duration in 3 of 5 axons, but this shortening could be duplicated by hyperpolarizing axons by $15 \mathrm{mV}$ in control solution. Thus we could not separate the effects of changing bath [K] from the effects of the accompanying changes in membrane potential.

\section{Intra-axonal injection of BAPTA slows action potential repolarization near terminals}

Figure $2 A$ shows that the late falling phase of the action potential recorded near 4-AP-treated motor terminals was prolonged by intra-axonal injection of the calcium buffer BAPTA. This effect increased with increasing durations of BAPTA injection $(n=$ 5). Membrane potential oscillations frequently appeared on the falling phase of the action potential; these developed into repetitive discharge in 3 of 5 axons tested. Our interpretation of these results is that BAPTA slows repolarization by binding intra-axonal $\mathrm{Ca}$ and thus preventing activation of a $\mathrm{Ca}$-dependent $\mathrm{K}$ conductance. Additional experiments showed that the effects of BAPIA injection on repolarization near terminals were reduced, but not totally eliminated, in axons bathed in solutions containing $1 \mathrm{~mm} \mathrm{Mn}$, or in solutions containing $4 \mathrm{~mm}$ $\mathrm{Mg}$ and no added $\mathrm{Ca}$. This result raises the possibility that the $\mathrm{Ca}$-dependent $\mathrm{K}$ conductance may be activated not only by $\mathrm{Ca}$ entering via the terminal axolemma, but also by $\mathrm{Ca}$ released from intra-terminal $\mathrm{Ca}$ stores (see later section of Results).

In 4-AP-treated axons impaled at sites remote from terminals, prolonged BAPTA injections increased action potential duration only slightly (Fig. $2 B, n=2$ ). This finding is consistent with the fact that depolarization-activated Ca currents are less prom- 
inent in the myelinated portion of the axon than in the motor terminals.

\section{In tetraethylammonium}

\section{Slow, Ca-dependent hyperpolarizing afterpotential}

TEA blocks not only the charybdotoxin-sensitive repolarizing current in motor terminals, but also several $\mathrm{K}$ currents present in the resting and depolarized axon (Barrett et al., 1988; AngautPetit et al., 1989). Addition of $10 \mathrm{~mm}$ TEA to lizard motor axons depolarizes the membrane potential by about $12 \mathrm{mV}$ and increases axonal input resistance and action potential duration (Barrett et al., 1988). In axons impaled near their motor terminals the action potential in $10 \mathrm{~mm}$ TEA is followed by Cadependent depolarizing afterpotentials (Morita and Barrett, 1989), labeled $D_{l}$ and $D_{2}$ in the upper left trace in Figure 3. The $\mathrm{D}_{1}$ afterpotential appears to be due to $\mathrm{Ca}$-dependent action potentials originating in the terminals and reflected electrotonically back to the axonal recording site (Morita and Barrett, 1989). In about $75 \%$ of axons bathed in $10 \mathrm{~mm}$ TFA these Ca-dependent afterpotentials were followed by a slow hyperpolarizing afterpotential (h.a.p.) that lasted several seconds (upper right trace, Fig. 3). In a sample of 25 axons showing this slow h.a.p. the average peak amplitude was $4.8 \pm 0.2 \mathrm{mV}$, and the average time to peak was $2.3 \pm 0.2 \mathrm{sec}$ (mean \pm standard deviation).

The slow h.a.p., as well as the $D_{1}$ and $D_{2}$ components of the depolarizing afterpotential, disappeared when $1 \mathrm{~mm}$ Mn was added to the bath (lower traces of Fig. 3) or perfused over the terminal region, or when $\mathrm{Ca}$ was omitted from the bathing solution (Fig. 5). (The monotonically decaying depolarizing afterpotential that remains in $\mathrm{Mn}$-containing or $\mathrm{Ca}$-free solutions is due to a passive discharge of the internodal axolemma; Barrett and Barrett, 1982.) The slow h.a.p. increased in amplitude and duration following elevation of bath [Ca] (Fig. 4).

Like the preceding $\mathrm{D}_{1}$ and $\mathrm{D}_{2}$ components of the depolarizing afterpotential (Morita and Barrett, 1989), the slow h.a.p. could not be recorded in the proximal end of axons mechanically cut off from their terminals, or in intact axons impaled at sites remote from motor terminals. The slow h.a.p. also disappeared when the stimulus frequency was increased from the normal 0.1 $\mathrm{Hz}$ up to $1 \mathrm{~Hz}$.

\section{The slow h.a.p. is pharmacologically distinct from posttetanic hyperpolarization}

High-frequency stimulation of peripheral axons is followed by a prolonged hyperpolarization thought to be mediated by an electrogenic Na,K-ATPase (reviewed by Thomas, 1972). This posttetanic hyperpolarization (p.t.h.) is distinct from the slow h.a.p. of Figures 3-5, for several reasons. First, as noted above, the slow h.a.p. could be recorded only at very low stimulation frequencies and only near motor terminals. Second, as shown in the middle row of traces in Figure 5, the Ca-free solutions that abolished the slow h.a.p. did not abolish the hyperpolarization recorded following a train of 10 action potentials at 10 Hz. Third, ouabain $(100 \mu \mathrm{M})$ blocked this posttetanic hyperpolarization (lowest trace, Fig. 5), but either did not reduce the slow h.a.p. $(n=3)$ or reduced it only slightly (Fig. $6, n=3$ ). This concentration of ouabain depolarized the resting potential by $2-3 \mathrm{mV}$. Applied depolarizing currents also reduced slow h.a.p. amplitude, perhaps by activating axonal potassium conductances and thus increasing the electrotonic distance between the terminals and the intra-axonal recording site. Higher [oua-
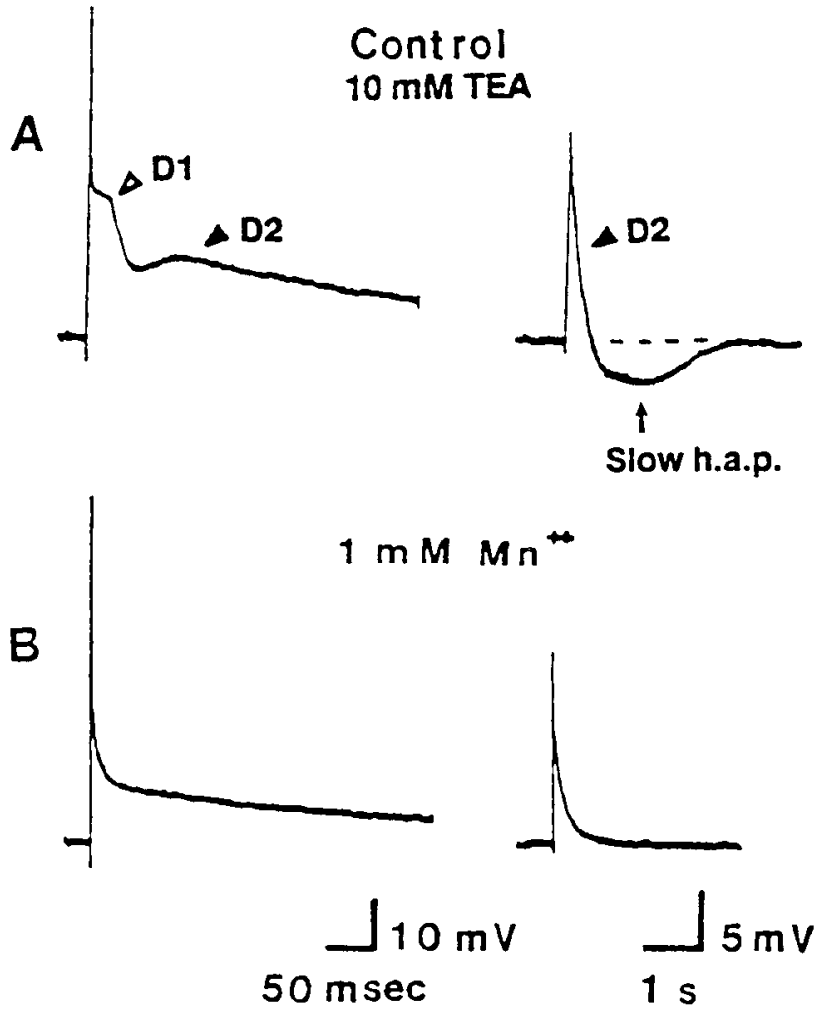

Figure 3. Ca-dependent afterpotentials recorded in $10 \mathrm{mM}$ TEA are abolished by $1 \mathrm{~mm} \mathrm{Mn}$. In $A$ the left record shows the Na-dependent action potential followed by depolarizing afterpotentials labeled $D_{l}$ and $D_{2}$. The right record, recorded at greater amplification and slower time sweep, shows $\mathrm{D}_{2}$ and the slow h.a.p. Matched records in $B$ were recorded in the same axon following addition of $1 \mathrm{~mm} \mathrm{Mn}$. Mn inhibited $\mathrm{D}_{1}$ and $\mathrm{D}_{2}$ and the slow h.a.p., leaving only the passive component of the depolarizing afterpotential. In this and all subsequent figures the action potential amplitude was truncated in records illustrating the slow h.a.p. Dashed line indicates baseline. Resting potential $-72 \mathrm{mV}$.

bain] (300 $\mu \mathrm{M}-1 \mathrm{~mm})$ produced a greater depolarization and reduced slow h.a.p. amplitude by up to $50 \%$.

Additional experiments demonstrated that an Mn-blockable slow h.a.p. could be evoked by injecting prolonged $(20 \mathrm{msec})$, intense depolarizing current pulses into axons bathed in $1-3 \mu \mathrm{M}$ tetrodotoxin. Since tetrodotoxin should eliminate most $\mathrm{Na}$ influx, this finding also suggests that the slow h.a.p. is not due to activation of an electrogenic pump by internal $\mathrm{Na}$.

\section{The slow h.a.p. appears to be mediated by K efflux}

To test whether the slow h.a.p. might instead be mediated by a TEA-resistant, Ca-dependent potassium current, we recorded the effects of varying bath [K]. Elevation of bath [K] from 4 to $10 \mathrm{~mm}$, which should decrease the driving force for $\mathrm{K}$ efflux, decreased the amplitude of the slow h.a.p. (Fig. $7 A$ ). Removal of bath $\mathrm{K}$, which should increase the driving force for $\mathrm{K}$ efflux, increased the slow h.a.p. (Fig. 7B). The enhancement of the slow h.a.p. in K-free solution was not due solely to the associated hyperpolarization of the axonal membrane potential, since other experiments indicated that a comparable hyperpolarization produced by passing current into axons bathed in normal [K] produced much less enhancement of the slow h.a.p. The increase in slow h.a.p. amplitude observed in K-free solutions also provides further evidence that this afterpotential is not mediated 
A

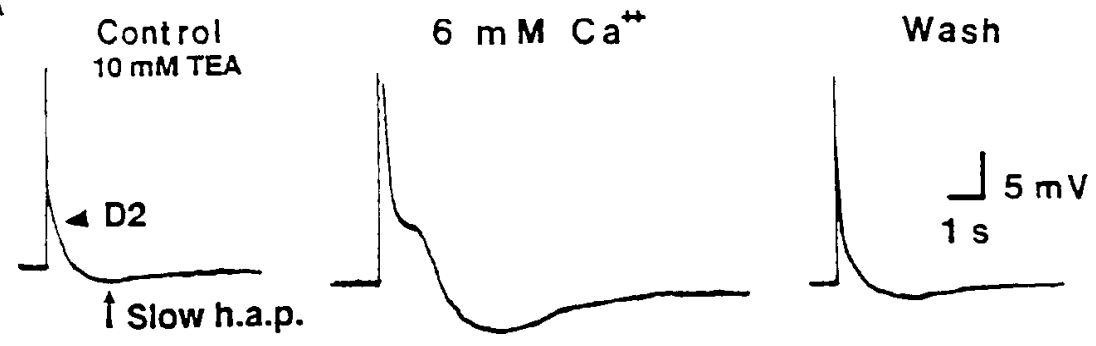

Figure 4. The slow h.a.p. becomes larger and longer with increasing bath [Ca]. $A$, Afterpotentials recorded in control $2 \mathrm{mM} \mathrm{Ca}(l e f t)$, after $5 \mathrm{~min}$ in 6 mM Ca (middle), and 7 min following return to $2 \mathrm{mM} \mathrm{Ca}$ (right). Resting potential $-70 \mathrm{mV} . B$, Mean peak amplitude of the slow h.a.p. as a function of bath [Ca] (note logarithmic scale). Amplitude was measured from the resting potential and expressed relative to the amplitude measured in $2 \mathrm{mM} \mathrm{Ca}(2.8$ $\pm 0.4 \mathrm{mV}, n=8)$. Each point gives the mean ( \pm standard deviation) of values measured from 4-6 axons. Throughout $A$ and $B 10$ mM TEA was present.

B

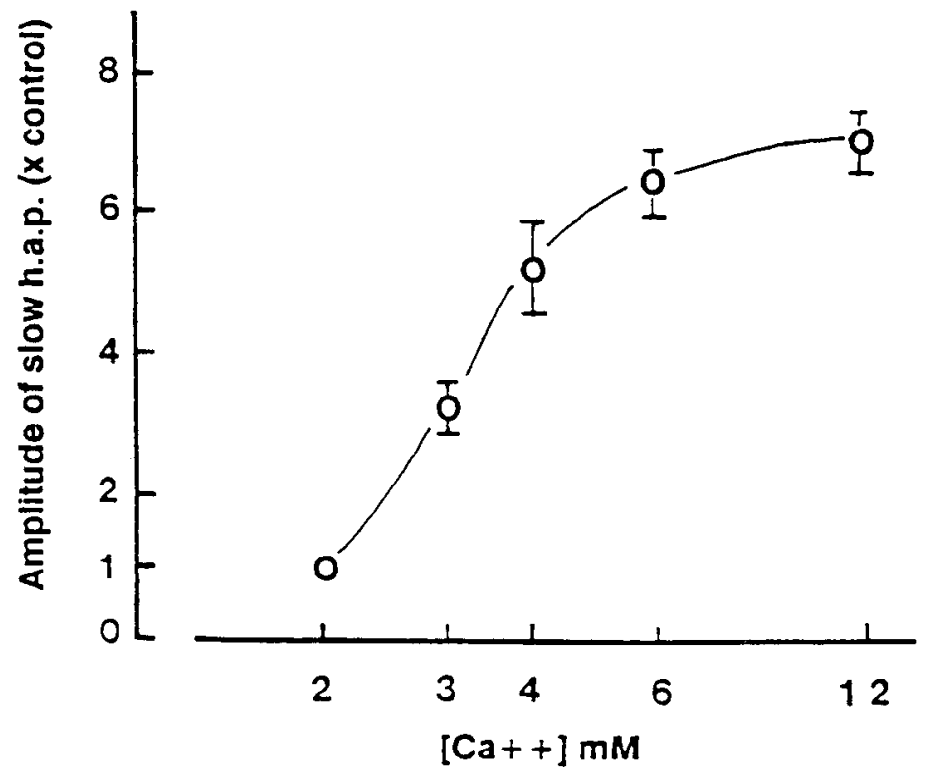

by the electrogenic Na,K-ATPase, since the activity of this pump is inhibited by removal of bath $\mathrm{K}$ (reviewed in Thomas, 1972).

The slow h.a.p. persisted in $\mathrm{Cl}$-free solution and thus is not mediated by an increased $\mathrm{Cl}$ conductance.

The data presented above are all consistent with the hypothesis that the slow h.a.p. is mediated by a TEA-resistant, Ca- dependent $\mathrm{K}$ efflux from motor terminals. However, our attempts to demonstrate a conductance increase during the slow h.a.p. and to demonstrate a reversal potential were inconclusive: steady injected currents changed the magnitude of the preceding Ca-dependent depolarizing potentials, and shorter current pulses injected during the slow h.a.p. affected other axonal channels

Figure 5. Ca-free solutions abolish the slow h.a.p., but not the posttetanic hyperpolarization (p.t.h.). The upper rows shows control records in $10 \mathrm{~mm}$ TEA, illustrating the action potential and $\mathrm{D}_{1}$ and $D_{2}$ depolarizing afterpotentials at left, and $\mathrm{D}_{2}$ and the slow h.a.p. at right. The middle row shows records collected 5-6 min after exposure to a solution containing $10 \mathrm{~mm}$ TEA, $10 \mathrm{~mm} \mathrm{Mg}$, and no added $\mathrm{Ca}$. This $\mathrm{Ca}$-free solution abolished $\mathrm{D}_{1}, \mathrm{D}_{2}$, and the slow h.a.p. (left and middle traces). The p.t.h. recorded following a train of stimuli (10 at $10 \mathrm{~Hz}$ ) persisted in this Ca-free solution (right trace), but was abolished following a $10 \mathrm{~min}$ exposure to $100 \mu \mathrm{M}$ ouabain (lower row, right). All records from the same axon. Ouabain depolarized the resting potential (originally -64 $\mathrm{mV}$ ) by $2-3 \mathrm{mV}$. Dashed lines indicate baselines.

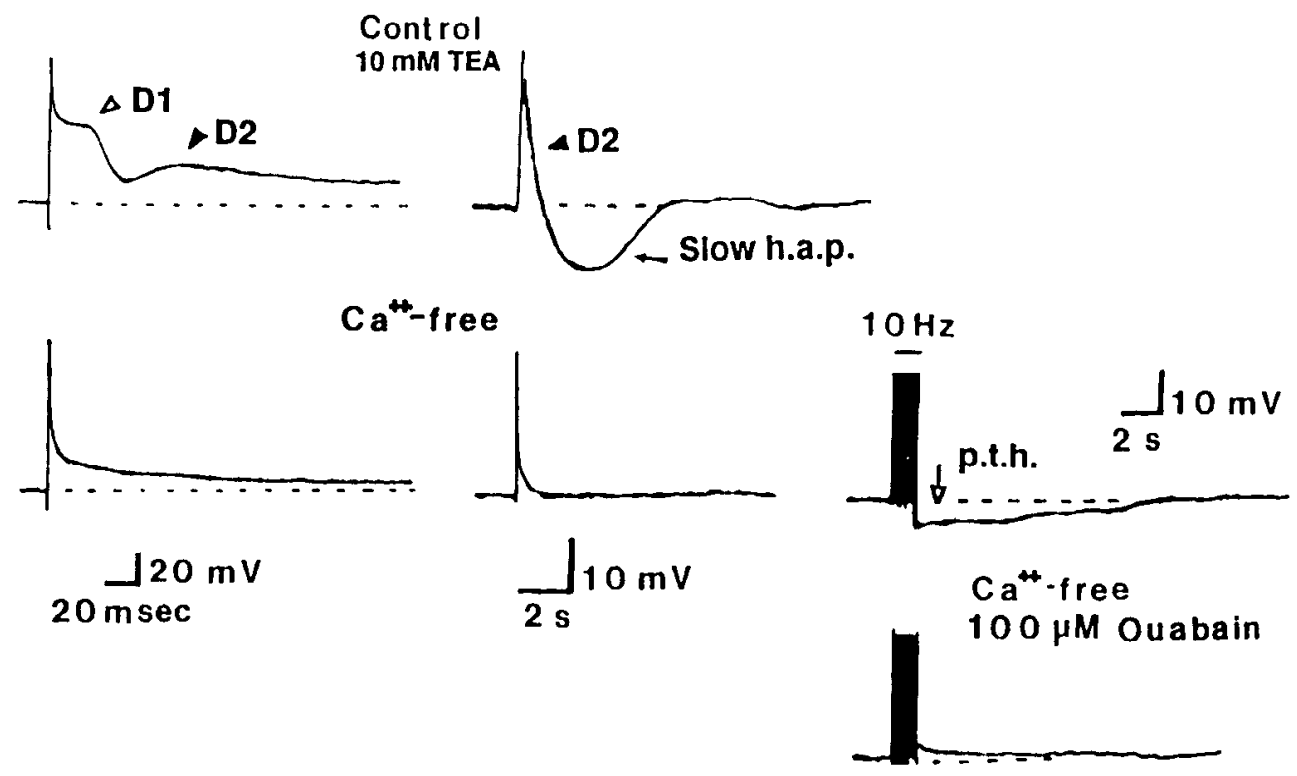




\section{Control}

$10 \mathrm{mM}$ TEA
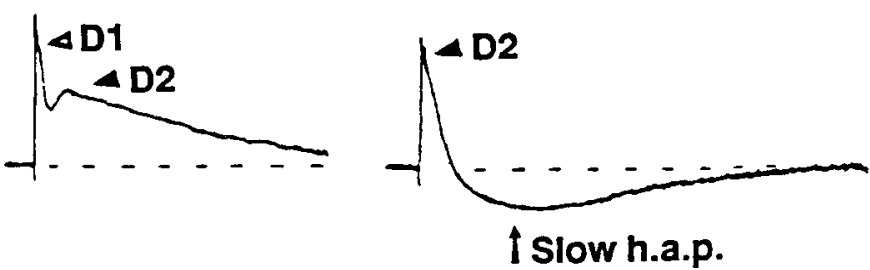

Ouabain

$100 \mu \mathrm{M}$

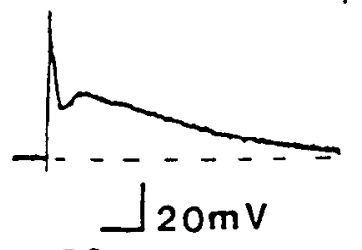

$50 \mathrm{msec}$

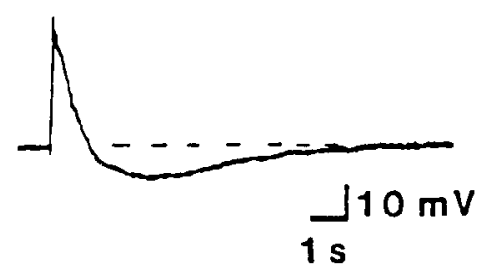

Figure 6. Ouabain does not abolish the slow h.a.p. Traces at left show the action potential and $D_{1}$ and $D_{2}$ components of the depolarizing afterpotential, and traces at right show (at increased amplification and slower time sweep) $\mathrm{D}_{2}$ and the slow h.a.p. Upper traces are controls in $10 \mathrm{~mm}$ TEA; lower traces were recorded $10 \mathrm{~min}$ after addition of 100 $\mu \mathrm{M}$ ouabain. Ouabain depolarized the resting potential (originally -75 $\mathrm{mV}$ ) by $2-3 \mathrm{mV}$. Dashed lines indicate baseline.

(including an inward rectifier), thus altering the electrical distance between the intra-axonal recording site and the motor terminals.

\section{Effects of $K$ channel blockers on the slow h.a.p.}

The next series of experiments was undertaken to determine how the slow h.a.p. is affected by agents known to alter K, Cadependent $\mathrm{K}$, and/or Ca currents in other preparations.

Increasing bath [TEA] from 10 to $20-25 \mathrm{~mm}$ increased the Ca-dependent depolarizing afterpotentials, but either abolished the slow h.a.p. (Fig. $8 \mathrm{~A}$ ) or reduced its amplitude and prolonged its time course. This suppression of the slow h.a.p. in very high [TEA] may be due to a low-affinity blockade of these (presumed)
$K$ channels and/or to enhancement of a slow depolarizing current. Four of six axons bathed in 20-25 mM TEA showed a very slow, Ca-dependent depolarizing afterpotential (labeled $D_{3}$ in Fig. 8A), which lasted $20 \mathrm{sec}$ or more. Other axons bathed in 20-25 mм TEA exhibited slow, spontaneous membrane potential oscillations.

In contrast, addition of $0.1-1 \mathrm{~mm} 4-\mathrm{AP}$ to a solution containing $10 \mathrm{~mm}$ TEA greatly increased the amplitude and duration of the slow h.a.p. (Fig. $8 B$ ). This effect was probably due in part to enhancement of $\mathrm{Ca}$ influx, since both $\mathrm{D}_{1}$ and $\mathrm{D}_{2}$ components of the depolarizing afterpotential were also greatly enhanced by 4-AP. The combination of $10 \mathrm{mM}$ TEA and $0.1-$ $1 \mathrm{~mm}$ 4-AP was often used in subsequent experiments to achieve a large, stable, slow h.a.p. (see Figs. 9A, 10B, 11, 12B).

\section{Apamin selectively blocks the slow h.a.p.}

Apamin (100 nM), which blocks certain Ca-dependent K channels, inhibited the slow h.a.p. selectively and reversibly (Fig. $9 A, n=4)$. In contrast, the slow h.a.p. persisted in the presence of $100 \mathrm{nM}$ charybdotoxin (Fig. $9 B$ ), a concentration 10 times greater than that which slowed action potential repolarization in 4-AP (Fig. $1 E$ ). Charybdotoxin might partially block the slower Ca-activated $\mathrm{K}$ channels thought to mediate the slow h.a.p., since the toxin-induced increase in the $D_{1}$ and $D_{2}$ components of the depolarizing afterpotential (which presumably reflects increased $\mathrm{Ca}$ influx) did not result in an increase in the slow h.a.p. Nonetheless, it seems clear that apamin blocks the slow h.a.p. much more effectively than charybdotoxin.

At first it seemed surprising to us that charybdotoxin had any effect on $D_{1}$ and $D_{2}$ in the presence of TEA, since TEA blocks most charybdotoxin-sensitive Ca-activated $\mathrm{K}$ channels. Our confusion was resolved by Miller's (1988) demonstration at the single channel level that charybdotoxin produces a much longerlasting blockade of Ca-activated $\mathrm{K}$ channels than does TEA and hence can inhibit channel activity even in the presence of TEA.

\section{Bay K 8644 selectively enhances the slow h.a.p.}

Bay K 8644 (100 nM), a dihydropyridine that prolongs the opening of L-type Ca channels (Hess et al., 1984), approximately

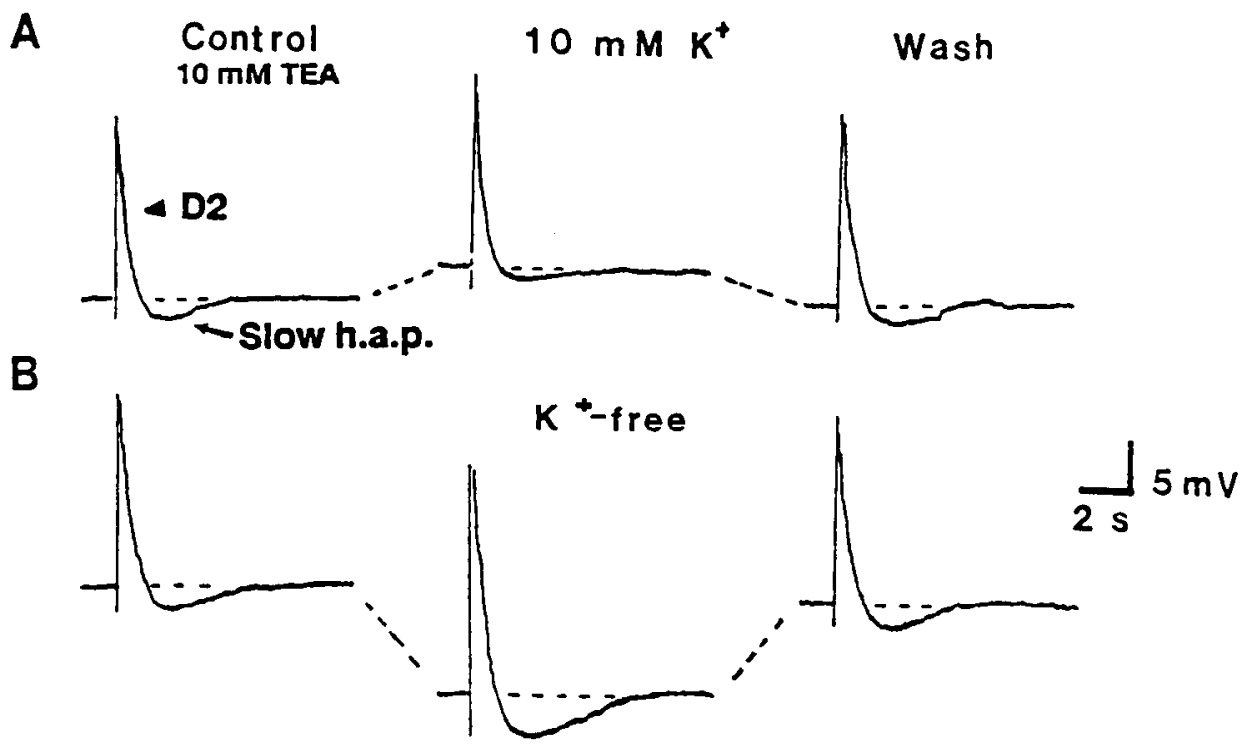

Figure 7. Variations in bath [K] change the amplitude of the slow h.a.p. recorded in $10 \mathrm{~mm}$ TEA. Traces show the $\mathrm{D}_{2}$ component of the depolarizing afterpotential and the slow h.a.p. recorded in the normal $4 \mathrm{mM} \mathrm{K}$ (left), $9 \mathrm{~min}$ after perfusion with $10 \mathrm{~mm} \mathrm{~K}$ (upper middle) or K-free solution (lower middle), and after return to $4 \mathrm{~mm} \mathrm{~K}$ (right). The resting membrane potential was $-72 \mathrm{mV}$ in $4 \mathrm{~mm} \mathrm{~K}$; it depolarized and hyperpolarized in high and low [K], as indicated by the dashed lines. 


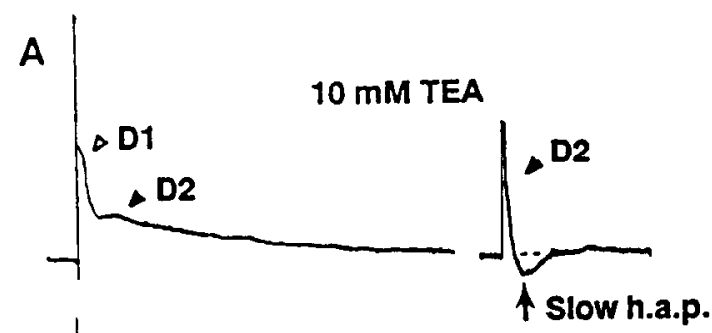

20 IM TEA
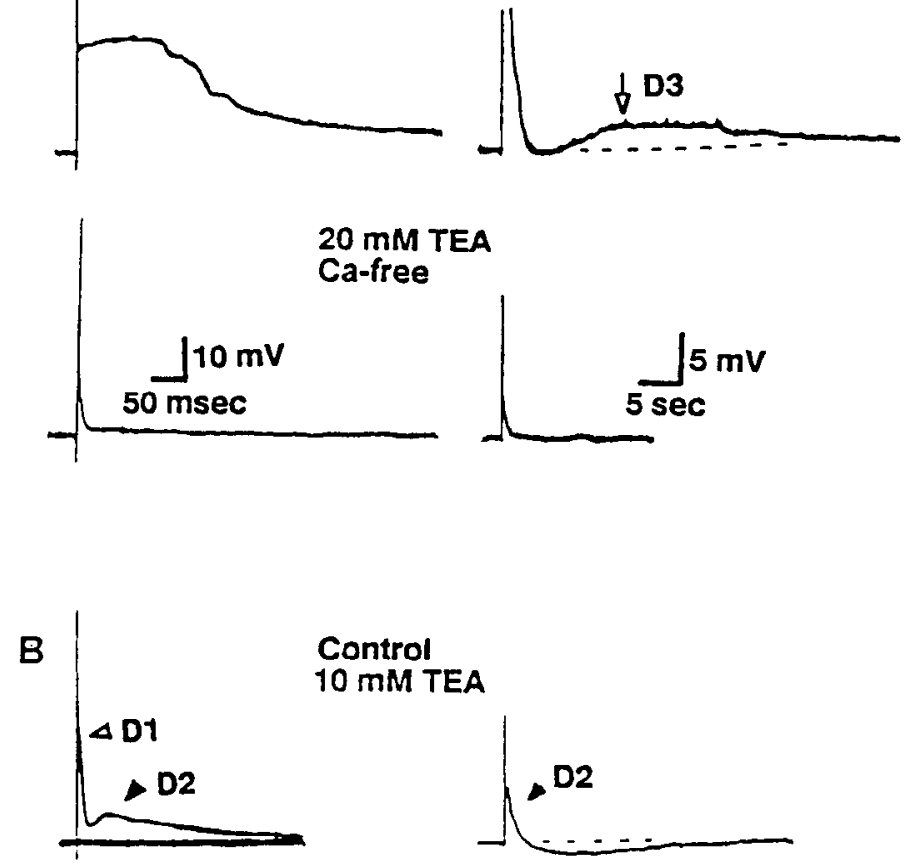

\section{Control $10 \mathrm{mM}$ TEA}

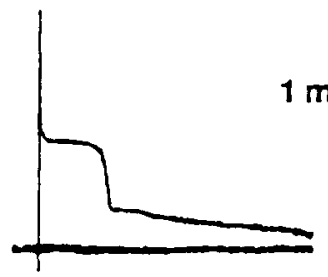

$1 \mathrm{mM}$ 4-AP
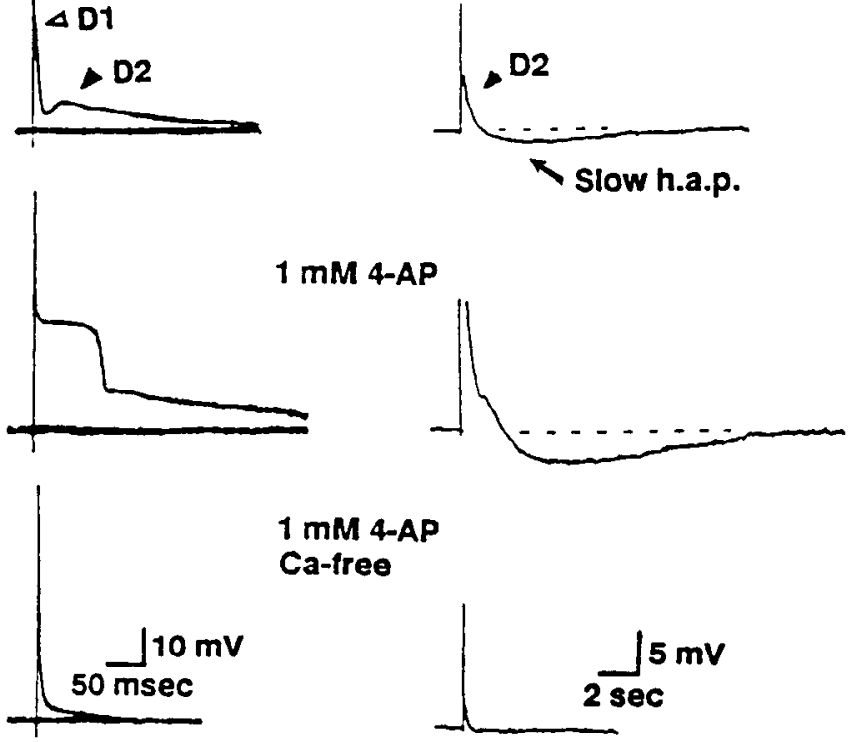

1 mM 4-AP

Ca-tree

Figure 8. Effects of elevated [TEA] $(A)$ and addition of $1 \mathrm{~mm} \mathrm{4-AP}$ $(B)$ on Ca-dependent afterpotentials. Traces at left show the action potential and $\mathrm{D}_{1}$ and $\mathrm{D}_{2}$ components of the depolarizing afterpotential, and traces at right show (at increased amplification and slower time sweep) $\mathrm{D}_{2}$ and the slow h.a.p. A, Upper traces recorded in 10 mM TEA, middle traces in $20 \mathrm{mM}$ TEA, and lower traces in Ca-free solution containing $20 \mathrm{~mm}$ TEA. Elevating TEA from 10 to $20 \mathrm{~mm}$ prolonged the $D_{1}$ component of the depolarizing afterpotential, but reduced or abolished the slow h.a.p. An additional, very slow, Ca-dependent depolarizing afterpotential (labeled $D_{3}$ ) often appeared. $B$, Upper traces show control records in $10 \mathrm{~mm}$ TEA, middle traces $10 \mathrm{~min}$ after addition of $1 \mathrm{~mm}$ 4-AP, and lower traces $10 \mathrm{~min}$ after removal of bath Ca (TEA and 4-AP still present). 4-AP prolonged the $D_{1}$ and $D_{2}$ components of the depolarizing afterpotential and increased and prolonged the slow h.a.p. These changes were reversible and repeatable in these and other axons. Dashed lines indicate baselines. Resting potentials in $10 \mathrm{~mm}$ TEA were $-64 \mathrm{mV}$ in $A$ and $-70 \mathrm{mV}$ in $B$. Increasing TEA from 10 to $20 \mathrm{~mm}$ depolarized the membrane potential by about $5 \mathrm{mV}$.
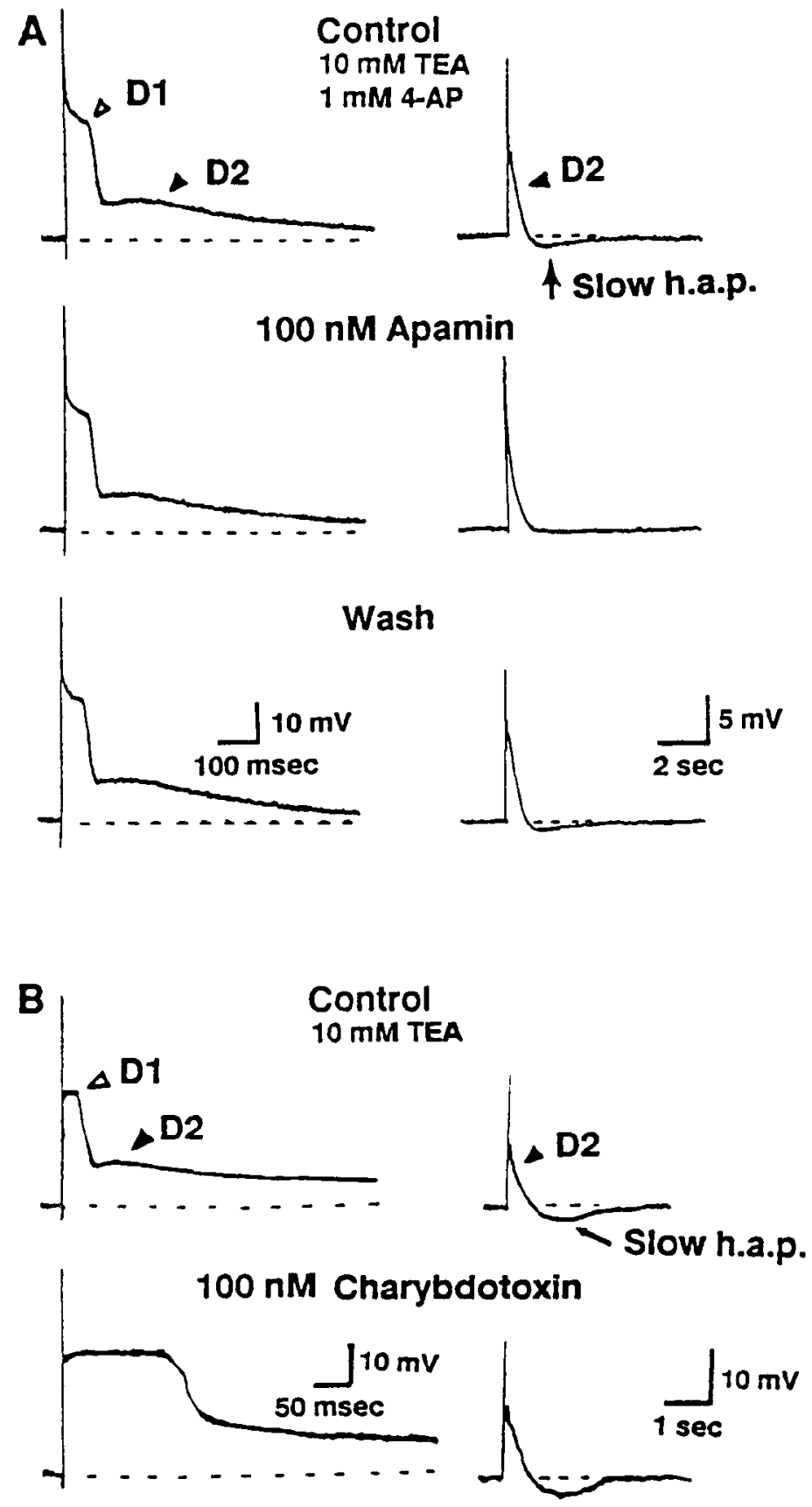

Figure 9. Effects of apamin $(A)$ and charybdotoxin $(B)$ on Ca-dependent afterpotentials. Traces at left show the action potential and $D_{1}$ and $\mathrm{D}_{2}$ components of the depolarizing afterpotential, and traces at right show (at increased amplification and slower time sweep) $\mathrm{D}_{2}$ and the slow h.a.p. A, Upper traces show controls in $10 \mathrm{~mm}$ TEA and $1 \mathrm{~mm}$ 4-AP. Middle traces werc rccorded $10 \mathrm{~min}$ after addition of $100 \mathrm{~nm}$ apamin, and right traces $7 \mathrm{~min}$ after washout of apamin. Apamin selectively blocked the slow h.a.p. $B$, Upper traces show controls in 10 mM TEA. Lower traces were recorded $6 \mathrm{~min}$ after adding $100 \mathrm{~mm}$ charybdotoxin to the bath. Charybdotoxin prolonged the $\mathrm{D}_{1}$ component of the depolarizing afterpotential, but had relatively little effect on $D_{2}$ or the slow h.a.p. Dashed lines indicate baselines. Resting potentials in control solutions were $-65 \mathrm{mV}$ in $A,-68 \mathrm{mV}$ in $B ; 100 \mathrm{~nm}$ charybdotoxin depolarized the membrane potential by $2-3 \mathrm{mV}$.

doubled the amplitude of the slow h.a.p. and prolonged its time course (Fig. 10A, $n=4$ ). Bay K 8644 also slightly enhanced the $\mathrm{D}_{2}$ component of the depolarizing afterpotential (Morita and Barrett, 1989). Nimodipine (1 $\mu \mathrm{M})$, a dihydropyridine that re- 
A

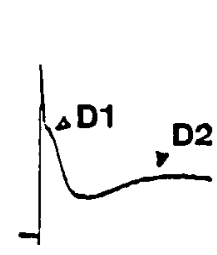

Control $10 \mathrm{mM}$ TEA
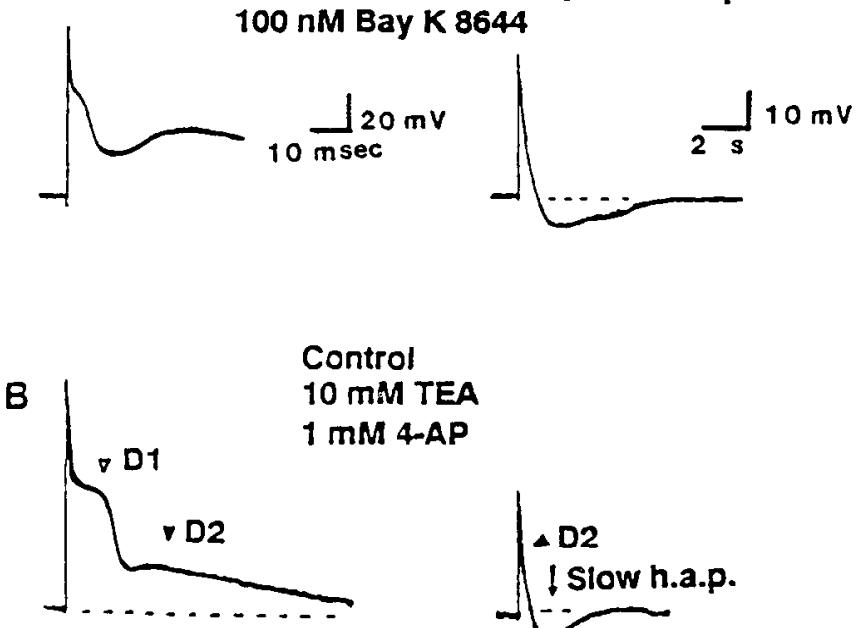

Control

$10 \mathrm{mM}$ TEA

I $\mathrm{MM}$ 4-AP
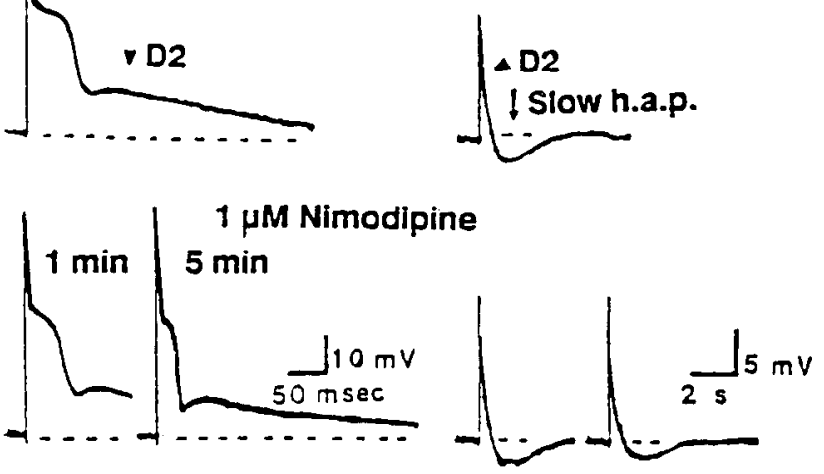

Figure 10. Effects of dihydropyridines Bay K $8644(1)$ and nimodipine $(B)$ on Ca-dependent afterpotentials. Traces at left show the action potential and $D_{1}$ and $D_{2}$ components of the depolarizing afterpotential, and traces at right show (at increased amplification and slower time sweep) $\mathrm{D}_{2}$ and the slow h.a.p. $A$, Upper traces show control response in $10 \mathrm{~mm}$ TEA. Lower traces were recorded after exposure to $100 \mathrm{~nm}$ Bay $\mathrm{K} 8644$, which produced a small increase in $\mathrm{D}_{2}$ and a larger increase in the slow h.a.p. B, Upper traces show control response in $10 \mathrm{~mm}$ TEA and $1 \mathrm{~mm}$ 4-AP. Lower traces show response after $1 \mathrm{~min}$ and $5 \mathrm{~min}$ exposures to $1 \mu \mathrm{M}$ nimodipine, which reduced the duration of $\mathrm{D}_{1}$, and reduced the amplitudes of $\mathrm{D}_{2}$ and the slow h.a.p. These dihydropyridine effects were reversible. Neither drug altered the passive voltage response to injected hyperpolarizing current. Dashed lines indicate baselines. Resting potentials were $-68 \mathrm{mV}$ in $A,-66 \mathrm{mV}$ in $B$.

duces the open time of L-type Ca channels (Hess et al., 1984), inhibited the $D_{1}$ and $D_{2}$ components of the depolarizing afterpotential and the slow h.a.p. (Fig. $10 B, n=4$ ). A lower concentration of nimodipine ( $100 \mathrm{nM}$ ) reduced the duration of $D_{1}$ (Morita and Barrett, 1989), but had no effect on $\mathrm{D}_{2}$ or the slow h.a.p. $(n=3)$. Nitrendipine $(0.1-1 \mu \mathrm{M})$, another dihydropyridine antagonist of L-type $\mathrm{Ca}$ channels, had no effect. Thus the inhibition of the slow h.a.p. by the Ca channel antagonists nimodipine and nitrendipine was less prominent than the enhancement of the slow h.a.p. by the Ca channel agonist Bay K 8644.

Intra-axonal injection of BAPTA reduces the slow h.a.p.

Injection of the Ca buffer BAPTA into axons bathed in TEA (with or without 4-AP) prolonged the $\mathrm{D}_{1}$ component of the
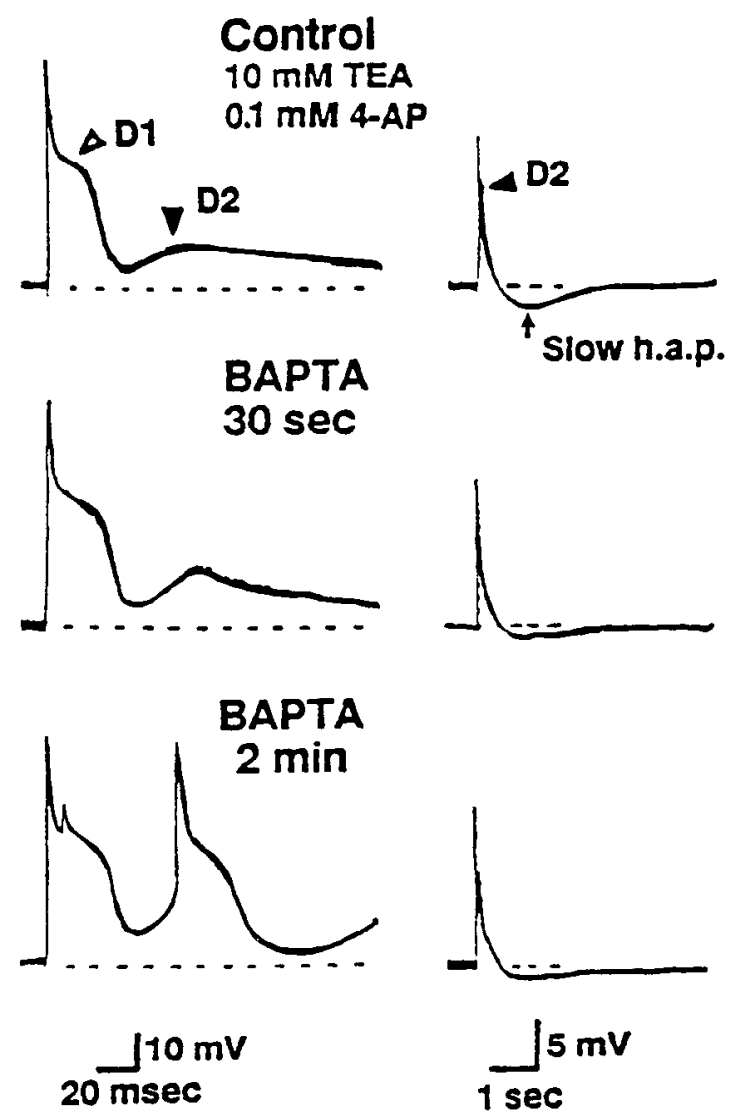

Figure 11. Effects of intra-axonal injection of BAPTA on afterpotentials measured in $10 \mathrm{~mm}$ TEA and $0.1 \mathrm{~mm}$ 4-AP. Traces at left show the action potential and $\mathbf{D}_{1}$ and $\mathbf{D}_{2}$ components of the depolarizing afterpotential, and traces at right show (at increased amplification and slower time sweep) $\mathrm{D}_{2}$ and the slow h.a.p. Upper traces show control records; middle and lower traces were recorded immediately following $30 \mathrm{sec}$ and $2 \mathrm{~min}$ injections of BAPTA from the recording electrode ( $0.5 \mathrm{nA}$ hyperpolarizing current). The $30 \mathrm{sec}$ BAPTA injection prolonged $\mathrm{D}_{1}$, increased the amplitude of $\mathrm{D}_{2}$, and reduced the amplitude of the slow h.a.p.; these changes were reversible during the $10 \mathrm{~min}$ rest that intervened between the middle and lower recordings. BAPTA injections of $2 \mathrm{~min}$ or more induced irreversible repetitive discharge that occurred both during and after the $\mathrm{D}_{1}$ plateau. Dashed lines indicate baselines. Resting potential was $-61 \mathrm{mV}$.

depolarizing afterpotential (and thus probably increased $\mathrm{Ca}$ influx into the terminals), but reduced the amplitude of the ensuing slow h.a.p. (Fig. 11). These effects were reversible following short (30 sec) injections of BAPTA, but longer BAPTA injections (2$5 \mathrm{~min}$ ) evoked prolonged bouts of repetitive discharge. This result would be expected if BAPTA bound some of the $\mathrm{Ca}$ that entered the depolarized terminal and thus reduced activation of the $\mathrm{Ca}$-dependent $\mathrm{K}$ current hypothesized to mediate the slow h.a.p. This reduction of a repolarizing current would prolong the terminal depolarization and promote repetitive discharge.

\section{The slow h.a.p. is enhanced by caffeine and inhibited by} procaine

We wondered whether the Ca-dependent $\mathrm{K}$ channels hypothesized to mediate the slow h.a.p. might be activated by $\mathrm{Ca}$ released from intraterminal stores, as well as by $\mathrm{Ca}$ entering across the terminal axolemma. To test this idea, we exposed the preparation to caffeine, which facilitates $\mathrm{Ca}$-induced $\mathrm{Ca}$ release from both muscle sarcoplasmic reticulum (reviewed by Endo, 1977; 
A

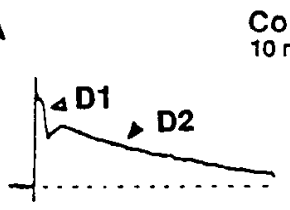

Control

$10 \mathrm{mM}$ TEA
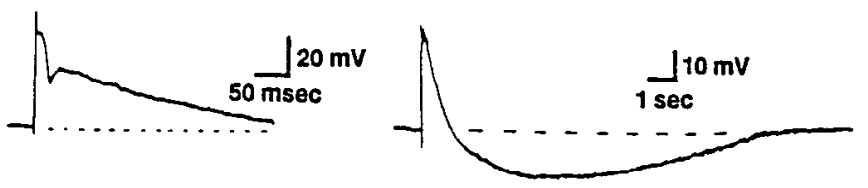

B

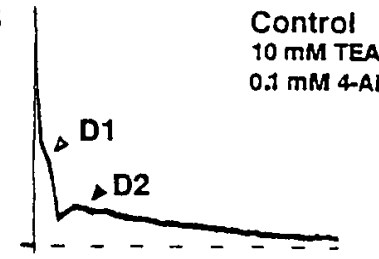

$100 \mu M$ Procaine

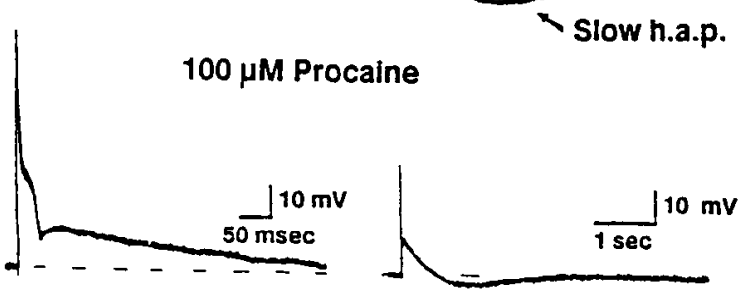

Figure 12. Effects of caffeine $(A)$ and procaine $(B)$ on Ca-dependent afterpotentials. Traces at left show the action potential and $D_{1}$ and $D_{2}$ components of the depolarizing afterpotential, and traces at right show (at increased amplification and slower time sweep) $\mathrm{D}_{2}$ and the slow h.a.p. A, Upper traces show controls in $10 \mathrm{mM}$ TEA; lower traces were recorded $10 \mathrm{~min}$ after addition of $1 \mathrm{~mm}$ caffeine. Caffeine selectively enhanced the slow h.a.p. $B$, Upper traces show controls in 10 mM TEA and $0.1 \mathrm{mM} 4-\mathrm{AP}$; lower traces were recorded after addition of $100 \mu \mathrm{M}$ procaine. Procaine selectively reduced the slow h.a.p. and sometimes produced a small $(3-6 \mathrm{mV})$ membrane hyperpolarization. Resting potentials: $-72 \mathrm{mV}$ in $A,-63 \mathrm{mV}$ in $B$. Dashed lines indicate baselines.

see, also, Rousseau and Meissner, 1989) and intraneuronal $\mathrm{Ca}$ stores (Kuba et al., 1983; Neering and McBurney, 1984; Lipscombe et al., 1988). Figure $12 A$ demonstrates that the slow h.a.p. recorded in $10 \mathrm{mM}$ TEA was selectively and dramatically enhanced by $0.1-1 \mathrm{~mm}$ caffeine. In this concentration range caffeine did not change the axonal membrane potential or passive properties, but prolonged exposure often led to muscle contractures, which dislodged the recording electrode.

Figure $12 B$ shows that $100 \mu \mathrm{M}$ procaine, which inhibits Cainduced $\mathrm{Ca}$ release from sarcoplasmic reticulum (reviewed by Endo, 1977), reduced the slow h.a.p. Similar reduction or abolition of the slow h.a.p. was observed over the concentration range of 30-100 $\mu \mathrm{M}$ procaine and was evident in both the presence and absence of caffeine. In 2 axons (including that shown in Fig. $12 B$ ) the inhibitory effect of $100 \mu \mathrm{M}$ procaine was selective for the slow h.a.p., but in 3 axons $100 \mu \mathrm{M}$ procaine also reduced the amplitude of the preceding depolarizing afterpotentials. Higher concentrations of procaine also reduced the amplitude of the initial fast $\mathrm{Na}$-dependent action potential.

\section{Discussion}

Ca-activated $K$ current contributing to action potential repolarization

In Table 1 the column labeled "Terminal fast $\mathrm{gK}(\mathrm{Ca})$ " summarizes pharmacological support for the hypothesis that a TEAand charybdotoxin-sensitive $\mathrm{Ca}$-activated $\mathrm{K}$ conductance contributes to action potential repolarization in motor terminals bathed in aminopyridines. Our findings with intra-axonal potential recordings agree with extracellular recordings from lizard, mouse, and frog motor terminals (Mallart, 1985; David and Yaari, 1986; Anderson et al., 1988; Lindgren and Moore, 1989). Other secretory cells show similar Ca-activated K currents, for example, brain synaptosomal membranes (Bartschat and Blaustein, 1985; Farley and Rudy, 1988; Reinhart et al., 1989) and certain endocrine cells (reviewed by Ozawa and Sand, 1986). A pharmacologically similar Ca-activated $\mathrm{K}$ current (sometimes abbreviated $\mathrm{I}_{C}$ ) contributes to action potential repolarization in the somata of bullfrog sympathetic neurons (Adams et al., 1982; MacDermott and Weight, 1982; Goh and Pennefather, 1987) and rat hippocampal CAl pyramidal cells (Lancaster and Nicoll, 1987; Storm, 1987). Single-channel recordings from a variety of preparations indicate that charybdotoxin-sensitive, Ca-activated $\mathrm{K}$ channels usually have a large single-channel conductance and require both depolarization and elevated intracellular $\left[\mathrm{Ca}^{2+}\right]$ for maximal activation (BK or maxiK channels, reviewed by Blatz and Magleby, 1987; Latorre et al., 1989).

\section{Ca-activated K current producing the slow h.a.p.}

The column labeled "Terminal slow $\mathrm{gK}(\mathrm{Ca})$ " in Table 1 summarizes pharmacological support for the hypothesis that the prolonged h.a.p. recorded near motor terminals bathed in TEA is produced by an apamin-sensitive, $\mathrm{Ca}$-activated $\mathrm{K}$ conductance distinct from the charybdotoxin-sensitive conductance described above. The current that produces the slow h.a.p. has a pharmacological profile similar to that of a subset of Ca-activated $\mathrm{K}$ channels characterized in rat skelctal muscle myotubcs (Romey and Lazdunski, 1984) and in a rat anterior pituitary cell line (GH3; Ritchie, 1987). These channels have a small unitary conductance and can be activated by intracellular $\mathrm{Ca}$ without concurrent depolarization (Blatz and Magleby, 1986; Lang and Ritchie, 1987). The current that generates the slow h.a.p. has not yet been detected in extraterminal or perineurial recordings from motor nerve terminals. However, prolonged TEA-resistant, apamin-sensitive, Ca-dependent hyperpolarizations have been reported in the somata of amphibian, reptilian, and mammalian spinal motoneurons (Barrett and Barrett, 1976; Krnjevic et al., 1978; Zhang and Krnjevic, 1987; Hounsgaard et al., 1988), as well as in the somata of other vertebrate peripheral and central neurons (Morita et al., 1982; Pennefather et al., 1985; Kawai and Watanabe, 1986; Lancaster and Adams, 1986; Goh and Pennefather, 1987; Schwindt et al., 1988).

The slow h.a.p., and the even more prolonged Ca-dependent depolarizations seen in $20 \mathrm{~mm}$ TEA (Fig. $8 A$ ), suggest that intracellular $\left[\mathrm{Ca}^{2+}\right]$ remains elevated for many seconds following stimulation of terminals bathed in TEA. Prolonged elevations of intracellular $\left[\mathrm{Ca}^{2+}\right]$, monitored with Ca-sensitive dyes, coincide with a $\mathrm{Ca}$-dependent slow h.a.p. in presynaptic terminals of barnacle photoreceptors (Stockbridge and Ross, 1984), and with a Ca-dependent posttetanic hyperpolarization in bullfrog sympathetic ganglion somata (Smith et al., 1983). Nerve ter- 
Table 1. Pharmacological profile of 4 potassium conductances (gK) thought to be present in lizard motor axons and/or motor terminals

\begin{tabular}{|c|c|c|c|c|}
\hline Agent & $\begin{array}{l}\text { Axonal } \\
\text { resting } \mathrm{gK}^{a}\end{array}$ & $\begin{array}{l}\text { Axonal delayed } \\
\text { rectifier } \mathrm{gK}^{b}\end{array}$ & $\begin{array}{l}\text { Terminal } \\
\text { fast } \mathrm{gK}(\mathrm{Ca})^{c}\end{array}$ & $\begin{array}{l}\text { Terminal } \\
\text { slow gK }(\mathrm{Ca})\end{array}$ \\
\hline $10 \mathrm{~mm}$ TEA & Decrease & Decrease & Decrease & \\
\hline $1 \mathrm{mM}$ 4-AP & n.e. & Decrease & & Increase \\
\hline Ca-free, $10 \mathrm{~mm} \mathrm{Mg}$ & n.e. & n.e. & Decrease & Decrease \\
\hline $6 \mathrm{~mm} \mathrm{Ca}$ & n.e. & n.e. & Increase & Increase \\
\hline $1 \mathrm{~mm} \mathrm{Mn}$ & n.e. & n.e. & Decrease & Decrease \\
\hline Intracellular BAPTA & n.e. & n.e. & Decrease & Decrease \\
\hline K-free & & & & Increase \\
\hline 10 nM charybdotoxin & n.e. & n.e. & Decrease & n.e. \\
\hline $100 \mathrm{~nm}$ apamin & & & n.e. & Decrease \\
\hline 100 nм Bay K 8644 & n.e. & & & Increase \\
\hline $1 \mu \mathbf{M}$ nimodipine & & & & Decrease \\
\hline $1 \mathrm{~mm}$ caffeine & n.e. & & sl. inc. & Increase \\
\hline $100 \mu \mathrm{M}$ procaine & sl. inc. & & & Decrease \\
\hline
\end{tabular}

sl. inc. = slight increase; $n . e .=$ little or no detectable effect; blank = could not be, or was not, tested.

${ }^{a}$ Decrease measured as depolarization of axonal resting potential with increased input resistance (Barrett et al., 1988); may be analogous to slow delayed rectifier described by Dubois (1981).

' Decrease measured as slowed repolarization of axonal action potential (see Barrett et al. 1988); may be analogous to fast delayed rectifiers described by Dubois (1981) and probably present in terminal axolemma as well (Angaut-Petit et al., 1989; Lindgren and Moore, 1989).

' Decrease measured as slowed repolarization of juxtaterminal action potential in 4-AP; probably analogous to terminal current described by Angaut-Petit et al. (1989) and Lindgren and Moore (1989).

${ }^{d}$ Decrease measured as decreased amplitude of slow hyperpolarizing afterpotential in juxtaterminal axon in $10 \mathrm{mM}$ TEA.

minals in other preparations stimulated singly or tetanically in Ca-containing media also show prolonged elevations of intracellular [ $\mathrm{Ca}^{2+}$ (squid: Miledi and Parker, 1981; Charlton et al., 1982; Aplysia L10 neuron: Connor et al., 1986; crayfish motor nerve: Delaney et al., 1989).

The effects of caffeine and procaine on the slow h.a.p. (Fig. 12) suggest that this afterpotential may be modified by Ca released from intraterminal stores. Membrane-bound compartments that might serve as intraterminal $\mathrm{Ca}$ stores have been identified in frog motor nerve terminals (Ornberg and Reese, 1980 ) and rat brain synaptosomes (McGraw et al., 1980). With the present limited evidence, this hypothesis is at best only tentative, since caffeine and procaine affect not only intracellular $\mathrm{Ca}$ release, but also certain enzymes, membrane receptors, and other ion channels. However, one possible explanation for the rather selective enhancement of the slow h.a.p. by the dihydropyridine Bay K 8644 (Fig. 10A) is that Bay K 8644 somehow facilitates an intraterminal Ca-releasing mechanism. In skeletal muscle the dihydropyridine receptor in the transverse tubular membrane is believed to be an essential component of the pathway linking plasma membrane depolarization to release of $\mathrm{Ca}$ from the sarcoplasmic reticulum (Rios and Brum, 1987). Intraterminal $\mathrm{Ca}$ release also provides a possible explanation for the disappearance of the slow h.a.p. at stimulation rates exceeding $0.1 \mathrm{~Hz}$, since intraterminal Ca stores might require several seconds to refill. Another possible explanation is that the slow h.a.p. is inhibited by prolonged exposure to elevated intracellular $\left[\mathrm{Ca}^{2+}\right.$.

With presently available recording techniques $\mathrm{Ca}$-activated repolarizing potentials and currents in motor terminals have been easiest to demonstrate using pharmacological agents that block other $\mathrm{K}$ channels and thus enhance $\mathrm{Ca}$ influx into the terminals. Although $\mathrm{Ca}$-dependent hyperpolarizations have not yet been detected under more physiological conditions, we hypothesize that activation of $\mathrm{Ca}$-dependent $\mathrm{K}$ channels during normal activity helps limit $\mathrm{Ca}$ influx and reduces the likelihood of terminal-initiated repetitive discharge.

\section{TEA- and 4-AP-sensitive $K$ currents in the myelinated portion of the axon}

Potentials recorded near motor terminals are also influenced by TEA- and 4-AP-sensitive $\mathrm{K}$ conductances in the myelinated portion of the motor axon. The properties of these axonal $\mathrm{K}$ conductances, as inferred from potential recordings presented in Barrett et al. (1988), are summarized in columns labeled "Axonal resting gK" and "Axonal delayed rectifier $\mathrm{gK}$ " in Table 1. The axonal resting $\mathrm{gK}$ is at least partially activated at the normal resting potential and is blocked by TEA but not by 4-AP. The axonal delayed rectifier $\mathrm{gK}$ contributes to the repolarization of the action potential in normal physiological saline and is blocked by both TEA and 4-AP. K channels with these hypothesized properties have been identified in voltage-clamp and single-channel studies of amphibian and lizard myelinated axons (Dubois, 1981; Angaut-Petit et al., 1989; Jonas et al, 1989).

The pharmacological sensitivities of these presumed axonal $\mathrm{K}$ currents help explain why the slow h.a.p. was not seen in axons exposed to 4-AP without TEA. TEA blocks at least 2 types of $\mathrm{K}$ channel that 4-AP does not: the axonal $\mathrm{K}$ channels open at the resting potential, and the charybdotoxin-sensitive, Ca-activated $\mathrm{K}$ channels in the terminal. These additional $\mathrm{K}$ channel-blocking abilities of TEA would be expected to increase total $\mathrm{Ca}$ influx into the terminals and to make a slow hyperpolarizing potential originating in the terminals easier to detect at the axonal recording site, due to the increase in axonal input resistance and space constant.

Table 1 summarizes data currently available for lizard motor axons and terminals, but it is probably incomplete. Conductances listed as axonal may also be present in the nerve terminal, 
and vice versa. Work of Dubois (1981) and of Jonas et al. (1989) suggests that the axonal delayed rectifier $\mathrm{gK}$ is produced by at least 2 different types of channel. In addition, Baker et al. (1987), Gordon et al. (1988), and Tabti et al. (1989) suggest that some vertebrate axons and terminals contain a depolarization-activated, Ca-independent $\mathrm{K}$ conductance that is sensitive to 4-AP but not to TEA. Lizard motor axons also have an inwardly rectifying current (Barrett et al., 1988), perhaps similar to that described by Baker et al. (1987) in rat spinal roots, by Eng et al. (1990) in rat optic nerve, and by Padjen and Poulter (1989) in frog peripheral axons. This multiplicity of $\mathrm{K}$ channels suggests a wide variety of mechanisms for altering the function of myelinated axons and their terminals.

\section{References}

Adams PR, Constanti A, Brown DA, Clark RB (1982) Intracellular $\mathrm{Ca}^{2+}$ activates a fast voltage sensitive $\mathrm{K}^{+}$current in vertebrate sympathetic neurones. Nature 296:746-749.

Anderson AJ, Harvey AL, Rowan EG, Strong PN (1988) Effects of charybdotoxin, a blocker of $\mathrm{Ca}^{2+}$-activated $\mathrm{K}^{+}$channels, on motor nerve terminals. Br J Pharmacol 95:1329-1335.

Angaut-Petit D, Benoit E, Mallart A (1989) Membrane currents in lizard motor nerve terminals and nodes of Ranvier. Pflügers Arch 415:81-87.

Baker M, Bostock H, Grafe P, Martius P (1987) Function and distribution of three types of rectifying channel in rat spinal root myelinated axons. J Physiol (Lond) 383:45-67.

Barrett EF, Barrett JN (1976) Separation of two voltage-sensitive potassium currents, and demonstration of a tetrodotoxin-resistant calcium current in frog motoneurons. .J Physiol (Lond) 255:737-774.

Barrett EF, Barrett JN (1982) Intracellular recording from vertebrate myelinated axons: mechanism of the depolarizing afterpotential. J Physiol (Lond) 323:117-144.

Barrett EF, Morita K, Scappaticci KA (1988) Effects of tetraethylammonium on depolarizing afterpotential and passive properties of lizard myelinated axons. J Physiol 402:65-78.

Bartschat DK, Blaustein MP (1985) Calcium-activated potassium channels in isolated presynaptic nerve terminals from rat brain. $\mathrm{J}$ Physiol 361:441-457.

Blatz A, Magleby K (1986) Single apamin-blocked Ca-activated K ${ }^{+}$ channels of small conductance in cultured rat skeletal muscle. Nature 323:718-720.

Blatz A, Magleby KL (1987) Calcium-activated potassium channels. Trends Neurosci 10:463-467.

Brigant JL, Mallart A (1982) Presynaptic currents in mouse motor endings. J Physiol (Lond) 333:619-636.

Charlton MP, Smith SJ, Zucker RS (1982) Role of presynaptic calcium ions and channels in synaptic facilitation and depression at the squid giant synapse. J Physiol (Lond) 323:173-193.

Connor JA, Kretz R, Shapiro E (1986) Calcium levels measured in a presynaptic neurone of Aplysia under conditions that modulate transmitter release. J Physiol (Lond) 375:625-642.

David G, Yaari Y (1986) Several potassium conductances modulate the excitability of frog motor nerve terminals. In: Calcium, neuronal function and transmitter release (Rahamimoff R, Katz B, eds). Boston: Martinus Nijhoff

Delaney KR, Zucker RS, Tank DW (1989) Calcium in motor nerve terminals associated with posttetanic potentiation. J Neurosci 9:35583567.

Dubois JM (1981) Evidence for the existence of three types of potassium channels in the frog Ranvier node membrane. J Physiol (Lond) 318:297-316.

Endo M (1977) Calcium release from the sarcoplasmic reticulum. Physiol Rev 57:71-108.

Eng DL, Gordon TR, Kocsis JD, Waxman SG (1990) Current-clamp analysis of a time-dependent rectification in rat optic nerve. J Physiol (Lond) 421:185-202.

Farley J, Rudy B (1988) Multiple types of voltage-dependent $\mathrm{Ca}^{2+}$ activated $\mathrm{K}^{+}$channels of large conductance in rat brain synaptosomal membranes. Biophys J 53:919-934.

Goh JW, Pennefather PS (1987) Pharmacological and physiological properties of the after-hyperpolarization current of bullfrog ganglion neurones. J Physiol (Lond) 394:315-330.

Gordon TR, Kocsis JD, Waxman SG (1988) Evidence for the presence of two types of potassium channels in the rat optic nerve. Brain Res 447:1-9.

Gundersen CB, Katz B, Miledi R (1982) The antagonism between botulinum toxin and calcium in motor nerve terminals. Proc R Soc London [Biol] 212:197-211.

Hess P, Lansman JB, Tsien RW (1984) Different modes of Ca channel gating behaviour favoured by dihydropyridine $\mathrm{Ca}$ agonists and antagonists. Nature 311:538-544.

Hounsgaard J, Kiehn O, Mintz I (1988) Response properties of motoneurones in a slice preparation of the turtle spinal cord. J Physiol (Lond) 398:575-589.

Jonas P, Bräu ME, Hermsteiner M, Vogel W (1989) Single-channel recording in myelinated nerve fibers reveals one type of $\mathrm{Na}$ channel but different K channels. Proc Natl Acad Sci USA 86:7238-7242.

Katz B, Miledi R (1969) Tetrodotoxin-resistant electric activity in presynaptic terminals. J Physiol (Lond) 203:459-487.

Kawai T, Watanabe M (1986) Blockade of Ca-activated K conductance by apamin in rat sympathetic neurones. $\mathrm{Br} \mathbf{J}$ Pharmacol 887 225-232.

Krnjevic K, Puil E, Werman R (1978) EGTA and motoneuronal afterpotentials. J Physiol (Lond) 275:199-223.

Kuba K, Morita K, Nohmi M (1983) Origin of calcium ions involved in the generation of a slow afterhyperpolarization in bullfrog sympathetic neurones. Pflügers Arch 399:194-202.

Lancaster B, Adams PR (1986) Calcium-dependent current generating the afterhyperpolarization of hippocampal neurons. J Neurophysiol 55:1268-1282.

Lancaster B, Nicoll RA (1987) Properties of two calcium-activated hyperpolarizations in rat hippocampal neurones. J Physiol (Lond) 389:187-203.

Lang DG, Ritchie AK (1987) Large and small conductance calciumactivated potassium channels in the $\mathrm{GH} 3$ anterior pituitary cell line. Pflügers Arch 410:614-622.

Latorre R, Oberhauser A, Labarca P, Alvarez O (1989) Varieties of calcium-activated potassium channels. Annu Rev Physiol 51:385399.

Lindgren CA, Moore JW (1989) Identification of ionic currents at presynaptic nerve endings of the lizard. J Physiol (Lond) 414:201222.

Lipscombe D, Madison DV, Poenie M, Reuter H, Tsien RW, Tsien RY (1988) Imaging of cytosolic $\mathrm{Ca}^{2+}$ transients arising from $\mathrm{Ca}^{2+}$ stores and $\mathrm{Ca}^{2+}$ channels in sympathetic neurons. Neuron 1:355-365.

MacDermott A, Weight FF (1982) Action potential repolarization may involve a transient, $\mathrm{Ca}^{2+}$-sensitive outward current in a vertebrate neurone. Nature 300:185-188.

Mallart A (1984) Presynaptic currents in frog motor endings. Pflügers Arch 400:8-13

Mallart A (1985) A calcium-activated potassium current in motor nerve terminals of the mouse. J Physiol (Lond) 368:577-591.

McGraw CF, Somlyo AV, Blaustein MP (1980) Localization of calcium in presynaptic nerve terminals. J Cell Biol 85:228-241.

Miledi R, Parker I (1981) Calcium transients recorded with arsenazo III in the presynaptic terminal of the squid giant synapse. Proc R Soc London [Biol] 212:197-211.

Miller C (1988) Competition for block of a Ca ${ }^{2+}$-activated $\mathrm{K}^{+}$channel by charybdotoxin and tetraethylammonium. Neuron 1:1003-1006.

Miller, C, Moczydlowski E, Latorre R, Phillips M (1985) Charybdotoxin, a protein inhibitor of single $\mathrm{Ca}^{2+}$-activated $\mathrm{K}^{+}$channels from mammalian skeletal muscle. Nature 313:316-318.

Morita K, Barrett EF (1988) Lizard motor nerve terminals have two calcium-dependent potassium conductances. Soc Neurosci Abstr 14: 70 .

Morita K, Barrett EF (1989) Calcium-dependent depolarizations originating in lizard motor nerve terminals. J Neurosci 9:3359-3369.

Morita K, North RA, Tokimasa T (1982) The calcium-activated potassium conductance in guinea-pig myenteric neurones. J Physiol (Lond) 329:341-354.

Neering IR, McBurney RN (1984) Role for microsomal Ca storage in mammalian neurones? Nature 309:158-160.

Ornberg RL, Reese TS (1980) A freeze-substitution method for localizing divalent cations: examples from secretory systems. Fed Proc 39:2802-2808. 
Ozawa S, Sand O (1986) Electrophysiology of excitable endocrinc cclls. Physiol Rev 66:887-952.

Padjen AL, Poulter MO (1989) A study of anomalous (inward) rectification in frog myelinated axons. Soc Neurosci Abstr 15:75.

Pennefather P, Lancaster B, Adams PR, Nicoll R (1985) Two distinct $\mathrm{Ca}$-dependent $\mathrm{K}$ currents in bullfrog sympathetic ganglion cells. Proc Natl Acad Sci USA 82:3040-3044.

Reinhart PH, Chung S, Levitan IB (1989) A family of calcium-dependent potassium channels from rat brain. Neuron 2:1031-1041.

Rios E, Brum G (1987) Involvement of dihydropyridine receptors in excitation-contraction coupling in skeletal muscle. Nature 325:717720.

Ritchic AK (1987) Two distinct calcium-activated potassium currents in a rat anterior pituitary cell line. J Physiol (Lond) 385:591-609.

Romey G, Lazdunski M (1984) The coexistence in rat muscle cells of two distinct classes of $\mathrm{Ca}^{2+}$-dependent $\mathrm{K}^{+}$channels with different pharmacological properties and different physiological functions. Biochem Biophys Res Commun 118:669-674.

Rousseau E, Meissner G (1989) Single cardiac sarcoplasmic reticulum $\mathrm{Ca}^{2+}$-release channel: activation by caffeine. Am J Physiol 256:H328$\mathrm{H} 333$.
Schwindt PC, Spain WJ, Foehring RC, Stafstrom CE, Chubb MC, Crill WE (1988) Multiple potassium conductances and their functions in neurons from cat sensorimotor cortex in vitro. J Neurophysiol 59: 424-449.

Smith SJ, MacDermott AB, Weight FF (1983) Detection of intracellular $\mathrm{Ca}^{2+}$ transients in sympathetic neurones using arsenazo III. Nature 304:350-352.

Stockbridge N, Ross WN (1984) Localized $\mathrm{Ca}^{2+}$ and calcium-activated potassium conductance in terminals of barnacle photoreceptor. $\mathrm{Na}$ ture 309:266-268

Storm JF (1987) Action potential repolarization and a fast afterhyperpolarization in rat hippocampal pyramidal cells. J Physiol 385 : 733-759.

Tabti N, Bourret C, Mallart A (1989) Three potassium currents in mouse motor nerve terminals. Pflugers Arch 413:395-400.

Thomas RC (1972) Electrogenic sodium pump in nerve and muscle cells. Physiol Rev 52:563-594.

Zhang L, Krnjevic K (1987) Apamin depresses selectively the afterhyperpolarization of cat spinal motoneurons. Neurosci Lett 74:5862. 